\title{
Evaluation of anthocyanin encapsulation efficiency into yeast cell by plasmolysis, ethanol, and ultrasound treatments using alone or in combination
}

\author{
${ }^{1,{ }^{*}}$ Lieu, M.D., ${ }^{1}$ Hoang, T.T.H., ${ }^{1}$ Nguyen, H.N.T. and ${ }^{2}$ Dang, T.K.T. \\ ${ }^{1}$ Faculty of Food Science and Technology, Ho Chi Minh City University of Food Industry, 140 Le Trong \\ Tan, Tay Thanh Ward, Tan Phu District, Ho Chi Minh City, Viet Nam \\ ${ }^{2}$ Department of Plant Cell Technology, Institute of Tropical Biology, 9/621 Ha Noi highway, Ho Chi Minh \\ City, Viet Nam
}

\begin{abstract}
Article history:
Received: 12 August 2019

Received in revised form: 9

November 2019

Accepted: 12 November

2019

Available Online: 11

December 2019
\end{abstract}

\section{Keywords:}

Anthocyanin,

Encapsulation,

Ethanol,

Plasmolysis,

Saccharomyces cerevisiae,

Ultrasonic

DOI:

https://doi.org/10.26656/fr.2017.4(2).283

\begin{abstract}
Anthocyanin is a water-soluble color compound of the flavonoid which was successfully encapsulation in Saccharomyces cerevisiae by plasmolysis, ethanol, and ultrasound treatments using alone or in combination in the first time. Treatment agents significantly enhanced the encapsulation efficiency of anthocyanin fluid. The encapsulation yield (EY) of the combined factors was higher than the individual impact factors. Ethanol 10\% (v/v) and ultrasound 180 seconds for the highest EY 40.22 $\pm 0.67 \%$, then ethanol $10 \%(\mathrm{v} / \mathrm{v})$ and $\mathrm{NaCl} 10 \%(\mathrm{w} / \mathrm{v})$ for $\mathrm{EY} 36.45 \pm 0.35 \%, \mathrm{NaCl} 10 \%$ and ultrasound for $\mathrm{EY} 32.14 \pm 0.98 \%$ lowest. The color stability evaluation of the capsules was carried out at $80^{\circ} \mathrm{C}$ for 30 minutes. The color lost rate was determined by the spectrometer. The color loss of samples with the un-treatment yeast was $20.45 \pm 1.21 \%$, higher than the treated sample. This suggests that anthocyanin encapsulation by yeast cell is efficient in overcoming the effects of high temperatures and having potential applications in food processing.
\end{abstract}

\section{Introduction}

Color is the main attribute which consumers are aware of food quality. Because of the natural pigment's safety and health benefits leading to customer demand have a trend to replace it for chemical color in food. Among the various biochemical secondary metabolites in plants, Anthocyanin appeal a lot of consideration of science in recent decades (Jain et al., 2015). Anthocyanins are water-soluble pigments widely distributed in plants, providing a wide range of color: red, pink, orange, mauve, magenta, and purple (Marpaung et al., 2017). The biological activities of anthocyanins to human's health and disease prevention (Wu et al., 2015). Hibiscus sabdariffa L. flowers are one of the potential anthocyanin sources because of the characteristics: cheap, safe and healthy (Grajeda et al., 2016). But natural color and anthocyanin in Hibiscus sabdariffa L. decompose during storage and is affected by temperature, humidity, $\mathrm{pH}$ (Nguyen et al., 2018). Therefore, a protective solution is necessaries to limit their color degradation and biological properties, one of which is the microencapsulation methods. In order to save natural color pigment, spray drying method with maltodextrin is a commonly used carrier, however, this method does not protect the desired optimal quality
(Robert et al., 2010). Recently researchers are interested in using yeast cells as microencapsulation materials because of its structure and nutritional benefits. Previous research has shown that the primary contraction process increases the ability to color encapsulation into yeast cells (Paramera et al., 2011). Similarly, color encapsulation ability into the yeast cell also showed a significant increase when treated by ethanol (Nguyen et al., 2018). This suggests that the effect on yeast cell membranes as well as on the osmotic pressure change of cells would increase the color encapsulation ability into the yeast cell. Besides, the effect on cell membranes can be carried out in many ways in which the ultrasound impact is also investigated in previous studies. The study of Guerrero et al. showed that the $20 \mathrm{kH}$ ultrasound with a large capacity of 60 to $90 \%$ had an impact on the cell walls as well as the structure of yeast, specifically into affected cells dynamic and small holes appear as well as fragments (Guerrero et al., 2001). This suggests that the impact of ultrasound significantly affects the yeast cell membrane and at a suitable impact level would be able to increase the color encapsulation ability into yeast cells. However, it is surprising that despite well-documented research on the bioactive compound encapsulation into yeast cells, there was no reported exist on the combined effects of ethanol, plasmolysis, and ultrasound on the 
anthocyanin encapsulation efficiency into yeast cells. Therefore, the effect of plasmolysis, ethanol, and ultrasound in individual or combined treatment on the anthocyanin encapsulation effect into yeast cells, as well as the effect of high temperature on the anthocyanin, were investigated in this study.

\section{Materials and methods}

\subsection{Plant material}

Hibiscus sabdariffa L. (Figure 1) from Binh Thuan province, the City is located at $10^{\circ} 56^{\prime} \mathrm{N} 108^{\circ} 6^{\prime} \mathrm{E}$ in the southeast region of Vietnam was used in this study. Calyces were dried at $45^{\circ} \mathrm{C}$ for $60 \mathrm{hrs}$, after removing washed and separated seeds. Dried calyces were crushed and sealed until used. Anthocyanin extraction from calyces was performed according to the description of Nguyen et al. (2018) with slight modifications. Briefly, a $20 \mathrm{~g}$ of calyces was mixed with $200 \mathrm{~mL}$ of distilled water for 20 mins at room temperature, using filter $(0.3 \mathrm{~mm})$ to separate the pulp and take the fluid to centrifuge $(5000 \mathrm{rpm})$ for 10 mins. The filtrate was concentrated by rotary evaporator at $60^{\circ} \mathrm{C} 650 \mathrm{mmHg}$ and stored at $4{ }^{\circ} \mathrm{C}$.

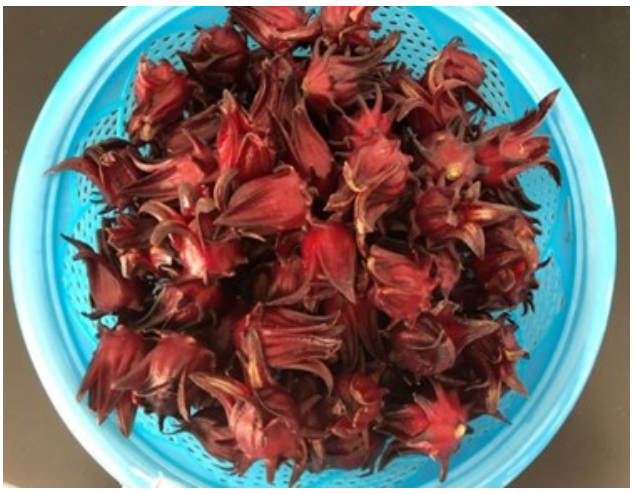

Figure 1. Hibiscus sabdariffa $\mathrm{L}$.

\subsection{Microorganisms and culture}

Saccharomyces cerevisiae was obtained from strain collection of Faculty of Food Science and Technology, Ho Chi Minh City University of Food Industry. The yeast cells were grown in Hansen agar for $24 \mathrm{hrs}$ at $30^{\circ}$ C. Then, the biomass was harvested by rinsing plates with $\mathrm{NaCl} 0.9 \%(\mathrm{w} / \mathrm{v})$ and centrifuge $(5000 \mathrm{rpm})$ for 10 mins. The yeast cells were used in the next encapsulation process

2.3 Evaluation of the effect of individual and combined of $\mathrm{NaCl}$, ethanol and ultrasonic treatment on the color microencapsulation of Saccharomyces cerevisiae

\subsubsection{Plasmolysis treatment}

The anthocyanin encapsulation procedure by yeast cells was carried out according to the description of Paramera et al. (2011) with slight modifications. Yeast $(0.5 \mathrm{~g})$ after are cultured, the biomass was treated with
$\mathrm{NaCl}(5 \% ; 10 \%$ and $15 \% \mathrm{w} / \mathrm{v})$, incubated in 24 hours, shaking rate $120 \mathrm{rpm}$ at $30^{\circ} \mathrm{C}$. The biomass was then collected by centrifugation of $5000 \mathrm{rpm}$ for $10 \mathrm{mins}$ and proceeded to mix with anthocyanin solution $(0.25 \mathrm{~g} / \mathrm{mL})$ in $1 \mathrm{hr}, 120 \mathrm{rpm}$ at $30^{\circ} \mathrm{C}$. The biomass was harvested by centrifugation, evaluated for encapsulation yield, and thermal stability of anthocyanin.

\subsubsection{Ethanol treatment}

The effect of ethanol on the anthocyanin encapsulation by yeast cells was performed according to the description of Nguyen et al. (2018) with slight modifications. Yeast cells $(0.5 \mathrm{~g})$ were mixed with the anthocyanin fluid $(0.25 \mathrm{~g} / \mathrm{mL})$ containing ethanol $(5 \%$; $10 \%$ and $15 \% \mathrm{v} / \mathrm{v}$ ) for $1 \mathrm{hr}, 120 \mathrm{rpm}$ at $30^{\circ} \mathrm{C}$. The biomass was harvested by centrifugation, evaluated for encapsulation yield, and thermal stability of anthocyanin.

\subsubsection{Ultrasonic treatment}

The effect of ultrasonic on the anthocyanin encapsulation by yeast cell was carried out in the following steps: yeast cells $(0.5 \mathrm{~g})$ was performed on equipment Sonics (maximum power $750 \mathrm{~W}$, frequency $20 \mathrm{kHz}$ ) at power $20 \%$ with ultrasonic times 60,180 and $300 \mathrm{~s}$ with a pulse $\mathrm{ON}$ time off, $10 \mathrm{~s}$ followed by a pulse OFF time of $10 \mathrm{~s}$. The fluid after the treatment ultrasound was centrifuged to collect yeast cells and mix with the anthocyanin fluid $(0.25 \mathrm{~g} / \mathrm{mL})$ for $1 \mathrm{hr}, 120 \mathrm{rpm}$ at $30^{\circ} \mathrm{C}$. The biomass was harvested by centrifugation, evaluated for encapsulation yield, and thermal stability of anthocyanin.

\subsubsection{Plasmolysis combines ethanol treatment}

Yeast cells were treated by $\mathrm{NaCl}$ and then mixed with the anthocyanin fluid $(0.25 \mathrm{~g} / \mathrm{mL})$ in ethanol $(5 \%$; $10 \%$ and $15 \% \mathrm{v} / \mathrm{v}$ ) in $1 \mathrm{~h}, 120 \mathrm{rpm}$ at $30^{\circ} \mathrm{C}$. The biomass was harvested by centrifugation, evaluated for encapsulation yield, and thermal stability of anthocyanin.

\subsubsection{Ultrasonic combines ethanol treatment}

Yeast cells were treatment by ultrasonic equipment and then mixed with the anthocyanin fluid $(0.25 \mathrm{~g} / \mathrm{mL})$ containing ethanol $(5 \% ; 10 \%$ and $15 \% \mathrm{v} / \mathrm{v})$ in $1 \mathrm{hr}, 120$ $\mathrm{rpm}$ at $30^{\circ} \mathrm{C}$. The biomass was harvested by centrifugation, evaluated for encapsulation yield, and thermal stability of anthocyanin.

\subsubsection{Plasmolysis combines ultrasonic treatment}

Yeast cells were treatment by ultrasound equipment. Then yeast cells were incubated with $\mathrm{NaCl}(5 \% ; 10 \%$ and $15 \%$ ) in $24 \mathrm{hrs}, 120 \mathrm{rpm}$ at $30^{\circ} \mathrm{C}$. The biomass was then collected by centrifugation of $5000 \mathrm{rpm}$ for $10 \mathrm{mins}$ and proceeded to mix with anthocyanin solution $(0.25 \mathrm{~g} /$ 
$\mathrm{mL}$ ) in $1 \mathrm{hr}, 120 \mathrm{rpm}$ at $30^{\circ} \mathrm{C}$. The biomass was harvested by centrifugation, evaluated for encapsulation yield, and thermal stability of anthocyanin.

\subsubsection{Control samples}

The control sample $(+)$ is a sample that did not take any treatment steps. Yeast cells $(0.5 \mathrm{~g})$ after were cultured, that was mixed with anthocyanin fluid $(0.25 \mathrm{~g} /$ $\mathrm{mL}$ ) for $1 \mathrm{hr}, 120 \mathrm{rpm}$ at $30^{\circ} \mathrm{C}$. The biomass was harvested by centrifugation, evaluated for encapsulation yield, and thermal stability of anthocyanin.

The control sample (-) was the anthocyanin fluid after the extraction process from Hibiscus sabdariffa $\mathrm{L}$. was used to evaluate the thermal stability of anthocyanin.

\subsection{Effect of temperature on the ability of} Saccharomyces cerevisiae to anthocyanin colors

Anthocyanin encapsulated yeast cells were incubated in the water bath at $80^{\circ} \mathrm{C}$ for 30 mins and evaluated for thermal stability of anthocyanin.

\subsection{Method of determining the content of Anthocyanin}

The method of determining the content of anthocyanin is based on the description of Nguyen et al. (2018) that used to determine the anthocyanin content by spectrometers $(520 \mathrm{~nm})$ calculated by Beer-Lamber formula:

$$
A C=\frac{A b s \times M \times D \times 10^{3}}{\varepsilon \times l}
$$

Where Abs: Absorbance of the diluted solution ( $\lambda$ $\max =520 \mathrm{~nm})$; M: Molecular weight: $465.2\left(\mathrm{~g} \cdot \mathrm{mol}^{-1}\right)$; D: Dilution Factor; $\varepsilon$ : (Delphinidin-3-glucosides): 23,700 (L. mole $\mathrm{cm}^{-1}$ ); and 1: Length of the optical path in the cuvette $(1 \mathrm{~cm})$

The encapsulation yield (EY\%) is determined by the formula:

$$
\operatorname{EY}(\%)=\frac{Q_{E}}{Q_{T}} \times 100
$$

Where $\mathrm{Q}_{\mathrm{E}}$ : was the amount $(\mathrm{g})$ of anthocyanin encapsulated and $\mathrm{Q}_{\mathrm{T}}$ : amount $(\mathrm{g})$ of Anthocyanin in the original sample

\subsection{Statistical analysis}

The data analysis was carried out using Statgraphics 15.1 software. Results from 3 individual experiments were used to calculate the mean and standard deviation of the cell counts and mean differences were established by Student's t-test at $\alpha=0.05$. The differences between means were considered significant at $p \leq 0.05$.

\section{Results and discussion}

The anthocyanin encapsulation ability into Saccharomyces cerevisiae cells by plasmolysis, ultrasound and ethanol treatments, as well as the effect of temperature on the ability to protect anthocyanin color in yeast cells, was presented in Figures 2, 3, 4 and 5. The result showed that in control samples with yeast cells without treatment, the anthocyanin encapsulation yield (EYs) was $9.75 \pm 1.17 \%$, lower $(p<0.05)$ than all treated samples. The study results also showed that anthocyanins microencapsulated yeast cells were stable in colors under the influence of the high temperature compared to the un -encapsulation color solution (loss rate of $30 \pm 0.53 \%$ ) as well as untreated yeast cell samples (loss rate of $20.45 \pm 1.21 \%$ ) (Figure 2). In the impact evaluation of individual factors, there was no difference $(p>0.05)$ between treatment agents. However, the color loss from ultrasonic treatment was higher than other factors (Figures 2, 3 and 4). The best result of the combination of ultrasound and plasmolysis for encapsulation yield of $30.15 \pm 0.98 \%$ was the lowest compared to other combinations, followed by the combination treatment between plasmolysis $(10 \% \mathrm{w} / \mathrm{v} \mathrm{NaCl})$ with ethanol $(10 \% \mathrm{v} / \mathrm{v})$, while the combination of ultrasound (180 seconds) with ethanol $(10 \% \mathrm{v} / \mathrm{v})$ achieved the highest encapsulation yield of $40.22 \pm 0.67 \%$.

The result showed that anthocyanins microencapsulated yeast cells were stable in colors under the influence of temperature compared to unencapsulation color solution as well as untreated yeast cell samples (Figures 2, 3, 4 and 5). The yeast cell treated by plasmolysis has a higher degree of sensitivity to high temperature than other remained samples (Figure 2). Among them, the combination of plasmolysis and ultrasound treatments contributes to the highest heat loss. The results also showed that the combination of ethanol with the other two treatment agents gave higher microencapsulation efficiency as well as increased the thermal stability of anthocyanins compared to other treatment agents remained. Although the combination of plasmolysis and ultrasound treatments has high encapsulation efficiency, the thermal stability of anthocyanins was lower (Figure 5).

The encapsulation yield of colored compounds by yeast cell plays an important role, helping to evaluate the encapsulation efficiency of yeast cells. The higher the encapsulation yield get, the lower the amount of product to be added to the food to achieve the desired color. Plasmolysis is the phenomenon of the water drain out of the cell, leading to the cell shrink and separates from the cell wall through the osmosis process. The extraction of water-soluble components (proteins, saccharides) out of 


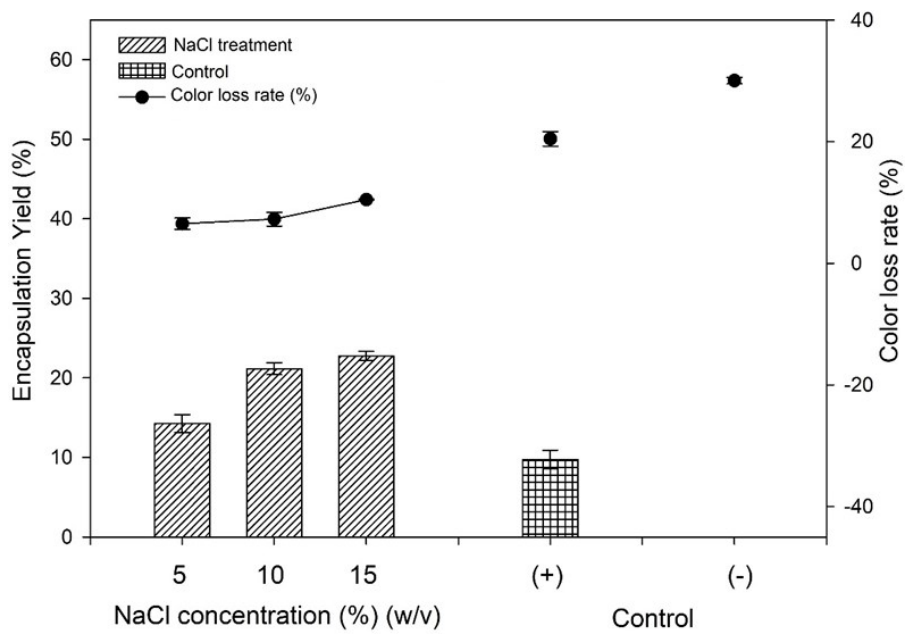

Figure 2. Effect of plasmolysis in individual treatment

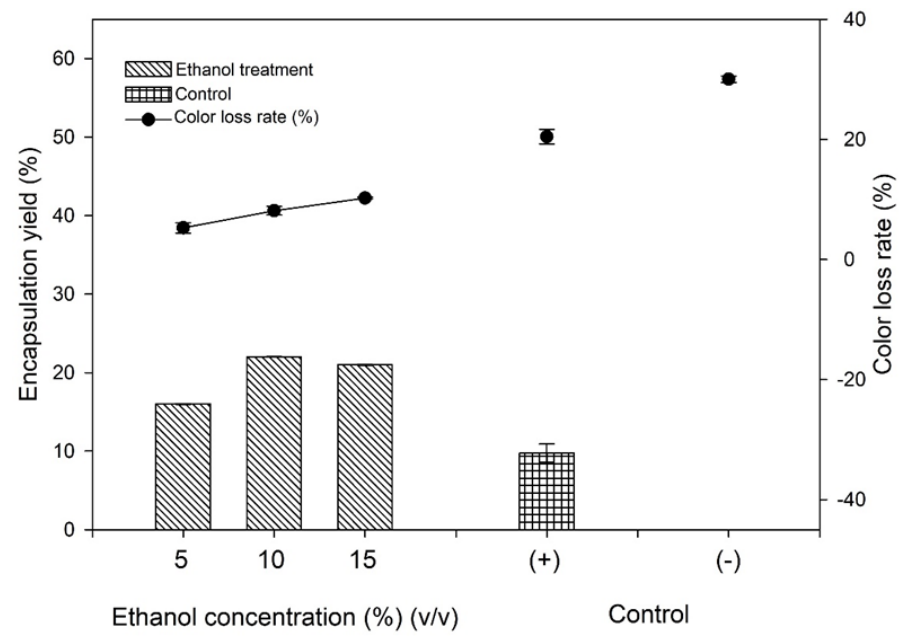

Figure 4. Effect of ethanol in individual treatment

the cell can increase the intracellular space, thus the yeast cell after the plasmolysis process was used for encapsulation that considers as empty bags to load compounds (Paramera et al., 2011). The study of Bishop et al. (1998) proved that the plasmolysis treatment helped to increase the encapsulation yield of the essential oil by two-fold compared to the untreated sample. Similarly, the treatment of plasmolysis with $\mathrm{NaCl}(5 \%$ $\mathrm{w} / \mathrm{v})$ showed that the encapsulation efficiency of acid chlorogenic by yeast cells reached $12.6 \%$ compared to the control gaining only $6.2 \%$ (Shi et al., 2007). Paramera et al. (2011) indicated that the encapsulation yield of curcumin by plasmolysis agent $(\mathrm{NaCl} 10 \% \mathrm{w} / \mathrm{v})$ reached $19.94 \%$, and there was no difference between $\mathrm{NaCl}$ concentrations $(10 \% ; 20 \% ; 30 \%$ and $40 \% \mathrm{w} / \mathrm{w})$ to the amount of the encapsulated curcumin. However, the results obtained from the current study that the concentration of $\mathrm{NaCl}(10 \% \mathrm{w} / \mathrm{v})$ gave the highest encapsulation yield of anthocyanin to yeast cells compared to the control, and the increase of $\mathrm{NaCl}$ concentration up to $15 \%(\mathrm{w} / \mathrm{v})$ causes the encapsulation yield to decrease (Figure 2). This may be due to the high $\mathrm{NaCl}$ concentration affecting the yeast cell membrane, which hinders the diffusion of color compounds into

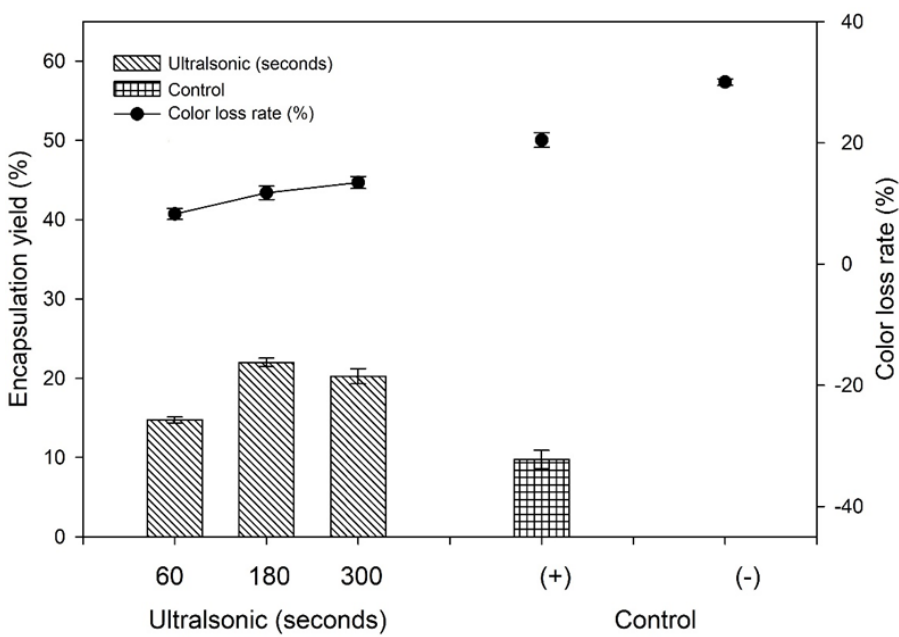

Figure 3. Effect of ultrasound in individual treatment

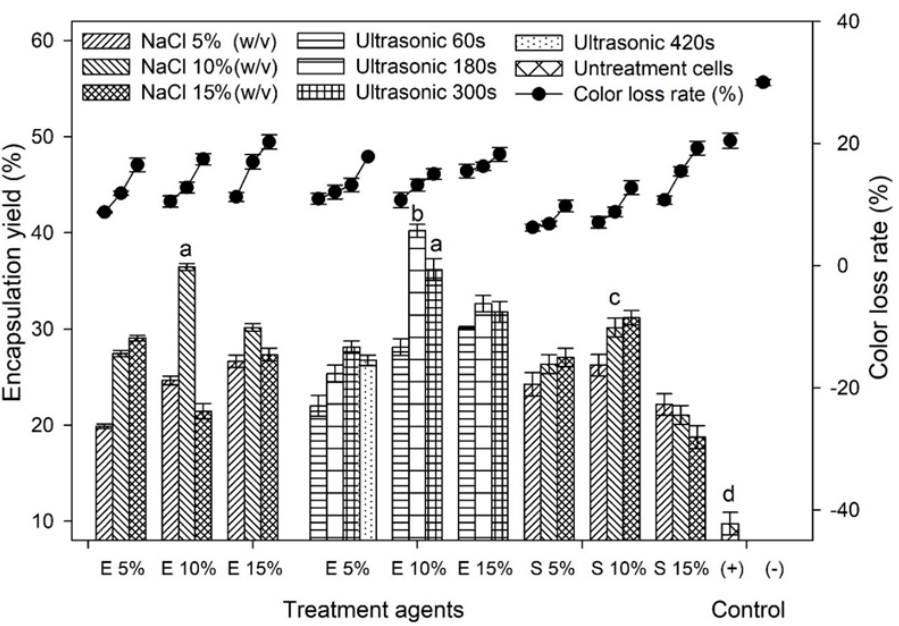

Figure 5. Effect of plasmolysis, ethanol, and ultrasound in combination treatments

yeast cells. As a result, the encapsulation yield of anthocyanin decreases after treatment.

The influence of ultrasound treatment on the yeast cell has been validated and published in previous studies. The ultrasound process produces mechanical effects at low frequencies, which makes small holes or small air chambers on yeast cells (Mason et al., 1990). The microorganism cell is significantly affected by the amplitude of the ultrasonic. When the amplitude increases, the affected area (small holes) increase, leading to increasing of inactivity cells (Guerrero et al., 2001). The study of Guerrero et al. (2001) indicated that the internal structure of the yeast cell was affected by ultrasonic leading to make the occurrence of fragments. However, the effect of the ultrasonic treatment on the ability of the anthocyanin encapsulation into yeast cells was poorly published in previous studies. The results of this study indicated that short-term ultrasound treatment has a significant impact on the encapsulation efficiency in which an ultrasound time of 180 seconds with a $20 \%$ of capacity made the encapsulation efficiency of $22 \pm 0.53 \%$ (Figure 3).

Ethanol affects the yeast cell membrane, which 
changes the permeability of the membrane and leads to a change in the transport of substances into the cell membrane. In the study of Paramera et al. (2011) ethanol caused curcumin encapsulation efficiency to be reduced on yeast cells because curcumin had a higher affinity for ethanol than water. However, in the current study showed that ethanol helped to increase the encapsulation efficiency of anthocyanin into yeast cells (Figure 4). This result agrees with the study of Nguyen et al. (2018) who suggested that ethanol $(10 \% \mathrm{v} / \mathrm{v})$ increases the encapsulation efficiency of color compounds into yeast by five times compared to the water. These show that the encapsulation efficiency of yeast cells by ethanol treatment depends on the type of encapsulated compounds. Ethanol affects yeast cell membranes by affecting water molecules, and lipid-lipid interactions, increasing the cell membrane fluidity (Paramera et al., 2011). The increase in ethanol concentration could grow the permeability of cell membranes, causing encapsulation efficiency to increase (Figure 2). However, the ethanol concentration increases leading to the encapsulation yield decreases sharply because the high ethanol concentration could affect as well as eliminate the permeability of the cell membrane.

The impact of plasmolysis or ethanol on the encapsulation efficiency of yeast cells has been published in previous studies. However, the research assessing the interaction between these factors has not yet been published. The results from this study showed that the combination of these factors helped the encapsulation efficiency of anthocyanin into yeast cells higher than the individual effects. The combination of ethanol $(10 \% \quad \mathrm{v} / \mathrm{v})$ and ultrasound $(180 \mathrm{~s})$ has significantly increased anthocyanin encapsulation yield compared to other pairs (Figure 3). The mechanism of combining these factors into encapsulation yield has not been published in previous studies. The anthocyanin encapsulation efficiency on yeast cells may be due to the interaction between the factors affecting the different mechanisms, which increases the permeability of the cell membrane to anthocyanin. Therefore, there was an increase in encapsulation efficiency (Figure 5).

In the food industry, the heating process is often used to extract, evaporate, dry, cook, and pasteurize food and beverages. However, the application of natural compounds in food technology faces many difficulties due to their sensitive characteristics with high temperatures in long process time. Muhamad et al. (2018) reported that high temperatures (blanching $95^{\circ}$ $\mathrm{C} / 3$ mins) combined with the pasteurization process of pure blueberry pre-treatment resulted in a loss of $43 \%$ of total anthocyanin monomeric compared to the initial fresh blueberries. In addition, high-temperature impact on anthocyanins resulting in incision products (gallic acid and protocatechuic) and accompanied by an increase in polymer color index, reduced red color and led to brown formation (Sinela et al., 2017). These suggested that anthocyanins are affected by the high temperature. In the plasmolytic process, the movement of water and dissolved compounds with water moves out of the cell (Paramera et al., 2011) together with the effect of ultrasound, an agent can produce small holes or small air chambers on yeast cells (Mason et al., 1990). This combined effect could cause the yeast cell membrane to be strongly affected, leading to increase the encapsulation yield. However, these effects on the cell membrane would be too strong that caused the anthocyanin fluid to be unstable and easily lost exposing to the high temperature (Figure 5). This was possibly due to both plasmolysis and ultrasound treatments affect cell membranes that injured yeast cells. In other hand, the effects of ethanol mainly change the permeability of cell membranes, leading to the treatment process with ethanol as an assistant agent increasing the encapsulation efficiency and heat resistance better than other treatment agents. The combination of ultrasonic and ethanol not only increases the encapsulation efficiency (Figure 6) but also reduces heat loss (Figure 5).

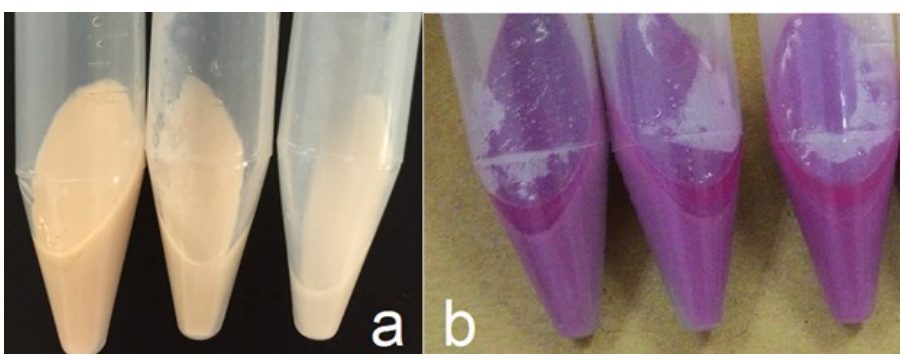

Figure 6. The biomass of yeast cell before (a) and after (b) encapsulation process

\section{Conclusion}

The study demonstrated successful encapsulated of anthocyanin compounds into yeast cells. The result showed that in control samples with yeast cells without treatment, the anthocyanin encapsulation efficacy was lower than all treated samples. Additionally, the high temperature significantly influenced the anthocyanin color fluid with color loss in the control sample higher than that of anthocyanin encapsulated. The effects of plasmolysis, ethanol, and ultrasound would have caused cell membranes to increase permeability, create hollow structures that make color molecules easily passive diffusion into cells. In the impact evaluation of individual factors, there was no difference between treatment agents. However, the color loss from ultrasonic treatments was higher than other factors. In studies of combined agents showed that the combination of ultrasonic and ethanol not only increase the 
encapsulation efficiency but also reduce the heat loss. Results in the current study indicated that the potential of application of yeast in anthocyanin encapsulation with the support of ultrasound and ethanol agents as well as apply in heat-treated food processing.

\section{References}

Bishop, J.R.P., Nelson, G. and Lamb, J. (1998). Microencapsulation in yeast cells. Journal of Microencapsulation, 15(6), 761-773. https:// doi.org/10.3109/02652049809008259

Grajeda-Iglesias, C., Figueroa-Espinoza, M.C., Barouh, N., Baréa, B., Fernandes, A., de Freitas, V. and Salas, E. (2016) Isolation and characterization of anthocyanins from Hibiscus sabdariffa flowers. Journal of Natural Products, 79(7), 1709-1718. https://doi.org/10.1021/acs.jnatprod.5b00958

Guerrero, S., López-Malo, A. and Alzamora, S.M. (2001) Effect of ultrasound on the survival of Saccharomyces cerevisiae: influence of temperature, $\mathrm{pH}$ and amplitude. Innovative Food Science and Emerging Technologie, 2(1), 31-39. https:// doi.org/10.1016/S1466-8564(01)00020-0

Jain, G. and Gould, K.S. (2015). Are betalain pigments the functional homologues of anthocyanins in plants? Environmental and Experimental Botany, 119, 48-53. https://doi.org/10.1016/ j.envexpbot.2015.06.002

Marpaung, A.M., Andarwulan, N., Hariyadi, P. and Nur Faridah, D. (2017) The colour degradation of anthocyanin-rich extract from butterfly pea (Clitoria ternatea L.) petal in various solvents at $\mathrm{pH} 7$. Natural Product Research, 31(19), 2273-2280. https://doi.org/10.1080/14786419.2017.1303689

Mason, T.J. (Ed.). (1990). A general introduction to sonochemistry. In Sonochemistry: The Uses of Ultrasound in Chemistry., p. 1-8. Cambridge, UK: The Royal Society of Chemistry.

Muhamad, I.I., Jusoh, Y.M., Nawi, N.M., Aziz, A.A., Padzil, A.M. and Lian, H.L. (2018). Advanced Natural Food Colorant Encapsulation Methods: Anthocyanin Plant Pigment. In Natural and Artificial Flavoring Agents and Food Dyes., p. 495-526. USA: Academic Press. https://doi.org/10.1016/B978-0-12811518-3.00015-6

Nguyen, T.T., Phan-Thi, H., Pham-Hoang, B.N., Ho, P.T., Tran, T.T.T. and Waché, Y. (2018) Encapsulation of Hibiscus sabdariffa L. anthocyanins as natural colours in yeast. Food Research International, 107, 275-280. https:// doi.org/10.1016/j.foodres.2018.02.044

Paramera, E.I., Konteles, S.J. and Karathanos, V.T.
(2011) Microencapsulation of curcumin in cells of Saccharomyces cerevisiae. Food Chemistry, 125(3), 892-902.

j.foodchem.2010.09.063

Robert, P., Gorena, T., Romero, N., Sepulveda, E., Chavez, J. and Saenz, C. (2010) Encapsulation of polyphenols and anthocyanins from pomegranate (Punica granatum) by spray drying. International Journal of Food Science and Technology, 45(7), 1386-1394 https://doi.org/10.1111/j.13652621.2010.02270.x

Shi, G., Rao, L., Yu, H., Xiang, H., Pen, G., Long, S. and Yang, C. (2007). Yeast-cell-based microencapsulation of chlorogenic acid as a watersoluble antioxidant. Journal of Food Engineering, 80 (4), 1060-1067. https://doi.org/10.1016/ j.jfoodeng.2006.06.038

Sinela, A., Rawat, N., Mertz, C., Achir, N., Fulcrand, H. and Dornier, M. (2017) Anthocyanins degradation during storage of Hibiscus sabdariffa extract and evolution of its degradation products. Food Chemistry, 214, 234-241. https://doi.org/10.1016/ j.foodchem.2016.07.071

Wu, J., Guan, Y. and Zhong, Q. (2015) Yeast mannoproteins improve thermal stability of anthocyanins at $\mathrm{pH}$ 7.0. Food Chemistry, 172, 121128 https://doi.org/10.1016/j.foodchem.2014.09.059 